\title{
Video Article \\ Profiling the Triacylglyceride Contents in Bat Integumentary Lipids by Preparative Thin Layer Chromatography and MALDI-TOF Mass Spectrometry
}

\author{
Evan L. Pannkuk ${ }^{1}$, Thomas S. Risch ${ }^{2}$, Brett J. Savary ${ }^{3}$ \\ ${ }^{1}$ Graduate Program of Environmental Science, Arkansas State University \\ ${ }^{2}$ Department of Biological Sciences, Arkansas State University \\ ${ }^{3}$ Arkansas Biosciences Institute and College of Agriculture and Technology, Arkansas State University
}

Correspondence to: Brett J. Savary at bsavary@astate.edu

URL: https://www.jove.com/video/50757

DOI: doi:10.3791/50757

Keywords: Chemistry, Issue 79, Molecular Biology, Biochemistry, Genetics, Anatomy, Physiology, Eukaryota, Bacterial Infections and Mycoses, Pathological Conditions, Signs and Symptoms, Diagnosis, Life Sciences (General), Triacylglyceride, Plagiopatagium, Integument, Sebaceous gland, White-Nose Syndrome, Matrix-Assisted Laser-desorption/lonization Time-of-Flight Mass Spectrometry, Thin-Layer Chromatography, animal model

Date Published: 9/5/2013

Citation: Pannkuk, E.L., Risch, T.S., Savary, B.J. Profiling the Triacylglyceride Contents in Bat Integumentary Lipids by Preparative Thin Layer Chromatography and MALDI-TOF Mass Spectrometry. J. Vis. Exp. (79), e50757, doi:10.3791/50757 (2013).

\section{Abstract}

The mammalian integument includes sebaceous glands that secrete an oily material onto the skin surface. Sebum production is part of the innate immune system that is protective against pathogenic microbes. Abnormal sebum production and chemical composition are also a clinical symptom of specific skin diseases. Sebum contains a complex mixture of lipids, including triacylglycerides, which is species-specific. The broad chemical properties exhibited by diverse lipid classes hinder the specific determination of sebum composition. Analytical techniques for lipids typically require chemical derivatizations that are labor-intensive and increase sample preparation costs. This paper describes how to extract lipids from mammalian integument, separate broad lipid classes by thin-layer chromatography, and profile the triacylglyceride contents using matrix-assisted laser desorption/ionization time-of-flight mass spectrometry. This robust method enables a direct determination of the triacylglyceride profiles among species and individuals, and it can be readily applied to any taxonomic group of mammals.

\section{Video Link}

The video component of this article can be found at https://www.jove.com/video/50757/

\section{Introduction}

Mammalian integumentary tissues include the epidermis, keratinous structures (e.g. hair and nails), and exocrine glands. Sebaceous-type exocrine glands are associated with hair follicles, which are collectively referred to as the pilosebaceous unit ${ }^{1}$. Sebaceous glands release an oily exudate onto the skin surface referred to as sebum. Sebum is composed largely of glycerolipids (e.g. triacylglycerides [TAGs]), free fatty acyls (FFAs), sterol/wax esters, and squalene. Sebum's chemical composition is species-specific ${ }^{2}$. In addition to being part of the innate immune system and providing antimicrobial function ${ }^{3}$, sebaceous lipids affect important physiological processes including evaporative water loss through skin $^{4}$, cellular integrity and gene regulation ${ }^{5}$, and drug absorption ${ }^{6}$. Sebaceous lipid compositions can also serve as disease markers. Altered ratios and amounts of sebaceous broad lipid classes are clinical signs of diseases such as acne vulgaris ${ }^{7}$, dandruff ${ }^{8}$, , seborrheic dermatitis ${ }^{8}$, asteatosis $^{9}$, among others ${ }^{10}$. Epidermal and hair tissues include variable profiles containing sterol and derivatives, TAGs, FFAs, ceramides, phospholipids, and other minor lipid components. Because integumentary lipids can function in disease processes, determining differences in chemical compositions of TAGs between healthy and diseased individuals may be useful for clinical diagnosis of disease.

Lipids are generally defined as being water-insoluble organic compounds with either nonpolar or nonpolar-polar substituents ${ }^{11}$. Lipid structures may be long hydrocarbon chains, oxygenated alkanes (including wax esters, FFAs, alcohols, ketones, and aldehydes), or complex ring structures such as cholesterol ${ }^{12}$. There are eight major classes of lipids based on structure (FFAs, glycerolipids [GL], glycerophospholipids [GP], sphingolipids [SP], sterol lipids [ST], prenol lipids [PR], saccharolipids [SL], and polyketides [PK]), which exhibit a wide range of chemical properties depending on the class ${ }^{13}$. Due to the wide variation in the chemical properties of lipid classes, direct profiling without prior derivatization of lipid molecules is desired. One emergent method in lipid research is thin-layer chromatography (TLC) combined with matrixassisted laser desorption/ionization time-of-flight mass spectrometry (MALDI-TOF MS) ${ }^{14}$.

MALDI-TOF MS is used extensively in proteomic research to identify proteins and associate them to specific amino acid sequences due to the highly accurate peptide ion mass "fingerprints" generated from trypsin-digested proteins ${ }^{15}$. MALDI-TOF MS can also be used to profile other biomolecule classes, including lipids such as TAGs ${ }^{16-18}$. MALDI requires the use of a matrix, typically an organic compound that contains aromatic and conjugated double bond structures. The matrix molecules serve to gently transfer the energy of the laser to the analytes, promote proton transfer, and produce singly charged gas-phase ions ${ }^{19-21}$. Ions are subjected to a high voltage field under high vacuum and accelerated into a TOF mass analyzer where ions are subsequently separated by differences in velocities that are proportional to their mass-to-charge ratios. Even very large biomolecules can be ionized with little fragmentation, producing singly charged molecular ion species for simplified spectrum 
analysis. The ability to analyze lipid molecules directly without prior derivatization has promoted ready adoption of MALDI-TOF MS in lipidomic research $^{18}$.

This paper presents a routine method to isolate and analyze integumentary lipids from the hair, sebaceous secretions and plagiopatagium of the Eastern red bat (Lasiurus borealis). This is used to determine interspecific variations in bat integumentary lipids to elucidate the disease process of White-Nose Syndrome (WNS) ${ }^{22}$. WNS is a fungal disease of bats and is caused by the newly described psychrophilic species Geomyces destructans ${ }^{23-25}$. WNS has caused the death of over 5 million North American cave bats and threatens the extinction of vulnerable bat species, with potential economic impacts of billions of dollars in damage to the agricultural industry ${ }^{26,27}$. To investigate the steps in G. destructans infection, lipids were extracted from the hair and wing tissues of Eastern red bats and separated into broad lipid classes by TLC to isolate the TAG fraction for subsequent analysis by MALDI-TOF MS. TAGs contain short acyl chains and are easily detected by MALDI-TOF MS with little matrix interference.

\section{Protocol}

CAUTION: Obtain in advance all requisite state and federal permits for handling, transporting, and storing bats. Approvals must also be obtained from your institutional animal care and use committee, as well as from your institutional biosafety committee. If live bats (or nervous system tissue) are to be handled, animal handlers should be vaccinated for rabies. Bats used in the current study were collected from the Ozark St. Francis National Forest, AR, during summer 2010 according to standard methods (Arkansas State University's Institutional Biosafety Committee approval \# 135349-1 $)^{28}$

\section{Tissue Treatment and Lipid Extraction}

1. Clean all instruments with methanol before and between tissue collection from different individuals. Trim hair (about $1.0 \mathrm{~g}$ ) from skin with a scissors and place in a $125 \mathrm{ml}$ Erlenmeyer flask. Sample sebum from wing surface by scrubbing skin with 4 - 6 cotton balls wetted with chloroform:methanol solvent (C:M; $3: 2 \mathrm{v} / \mathrm{v})$, and place these in a separate flask.

2. Extract tissue with $10 \mathrm{ml}$ of $\mathrm{C}: \mathrm{M}(2: 1 \mathrm{v} / \mathrm{v})$ containing $0.5 \%$ butylated hydroxytoluene $(\mathrm{BHT})$ to prevent oxidation ${ }^{29}$. Only use HPLC quality solvents.

3. After $2 \mathrm{hr}$, add about $0.5 \mathrm{~g}$ anhydrous sulfate to each flask, mix briefly, and collect the solvent by filtering through filter paper.

4. Repeat steps 1.2 and 1.3 twice. Once with 1:1 C:M and sequentially with 1:2 C:M. Pool filtrates together.

5. Evaporate the pooled filtrates under a stream of $\mathrm{N}_{2}$, determine dry weight, and dissolve the lipid residue in $3: 2 \mathrm{C:M}$ (with $0.5 \% \mathrm{BHT}$ ) to a concentration of $10 \mathrm{mg} / \mathrm{ml}$. Store sample in glass vials at $-20{ }^{\circ} \mathrm{C}$. It is generally best to analyze samples within one month after sample collection and to minimize freeze-thaw cycles.

\section{Lipid Separation by Preparative Thin-layer Chromatography}

1. Prepare in advance solvent-washed $1.5 \mathrm{ml}$ microcentrifuge tubes by filling with $3: 2 \mathrm{C}: \mathrm{M}$, rinsing with acetone, and air-drying. This is done to remove plasticizers that can interfere with later mass spectrometry analysis. Store sample tubes in a dust-free container and handle these tubes only with gloves to prevent contamination from skin oils.

2. Activate the TLC plate by first pre-developing it with 3:2 C:M. Add enough solvent to the TLC chamber to a depth of $1 \mathrm{~cm}$, then place plate in the chamber (close with glass lid) and allow the solvent to run completely to the top of the plate. This takes about $45 \mathrm{~min}$.

3. Remove the plate and dry in a fume hood until solvent evaporates (about $15 \mathrm{~min}$ ), then place in an oven for at least $10 \mathrm{~min}$ at $120{ }^{\circ} \mathrm{C}$. Place a pencil mark at the top of the plate to maintain orientation when samples are applied. Place a straight pencil line, $1.5 \mathrm{~cm}$ from the bottom edge of the plate, to mark the baseline where the sample and standards will be placed.

4. Prepare TLC chamber by cutting a piece of filter paper large enough to line the two short walls and one long wall. Place the filter paper liner into the chamber. It will fully wet when solvent is added to the chamber.

5. Prepare $100 \mathrm{ml}$ of the mobile phase solvent, which is hexane:diethyl ether:acetic acid (H:E:A;80:20:2 v/v/v). Pour solvent into the chamber to give a depth of about $1 \mathrm{~cm}$. Cover with the glass lid, using a silicone grease seal along the top edge of the chamber. Allow the chamber to equilibrate overnight before use.

6. Apply the sample manually to the prepared plate with a capillary tube or pipette as a continuous streak from about $1.5 \mathrm{~cm}$ from one edge to $1.5 \mathrm{~cm}$ to the other edge. An automated sample applicator is preferred since it will load the sample in a more homogenous streak. Use the outer lanes of TLC plate to spot about $20 \mu \mathrm{l}$ mixture of sterol, FFAs, TAGs, and sterol ester standards (use at $10 \mathrm{mg} / \mathrm{ml}$; premade mixtures can be obtained).

7. Place the loaded TLC plate into the equilibrated chamber, close with the lid, and develop the plate until the solvent runs to the top edge. This takes about $45 \mathrm{~min}$ with the mobile phase described here. Remove the plate from the chamber and allow the excess solvent to evaporate from the plate in a fume hood for about $1 \mathrm{~min}$.

8. Spray with $0.05 \%$ rhodamine $6 \mathrm{G}$ in $95 \%$ ethanol. Visualize lipid bands under a long wavelength ultraviolet lamp. Mark with a pencil the Rf position for the fluorescent bands resolved in the sample and standards. A photographic record can be taken at this point.

9. Identify the band corresponding with the TAG standard and remove it from the plate by scraping the silica off with a spatula onto a large piece of glassine weigh paper. Transfer silica to a $1.5 \mathrm{ml}$ solvent-washed microcentrifuge tube.

10. Add $1.0 \mathrm{ml}$ of 3:2 C:M solvent to the sample tube, sonicate for $1 \mathrm{~min}$, pellet the silica by centrifugation, and then transfer the solvent into a new pre-weighed tube. Repeat the previous step, pool the filtrates, and evaporate the solvent under a stream of $\mathrm{N}_{2}$.

11. Store the dried residue containing TAGs under $\mathrm{N}_{2}$ in the dark at $4{ }^{\circ} \mathrm{C}$ while additional tissue samples are separated by TLC. Rhodamine $6 \mathrm{G}$ is present in samples, but it is insoluble in hexane and is removed during sample dissolution immediately before MS analysis. 


\section{TAG Analysis by MALDI-TOF MS}

1. Prepare a fresh a-cyano-4-hydroxy-cinnamic acid (CHCA) matrix solution by dissolving $10 \mathrm{mg} \mathrm{CHCA}$ in $1 \mathrm{ml}$ solvent (49.5\% ethanol, $49.5 \%$ acetonitrile, and $1 \%$ aqueous $0.1 \%$ TFA).

2. Prepare adrenocarticotropic hormone (ACTH; $18-39$ clip, $2465.1989 \mathrm{Da})$ for instrument resolution and sensitivity testing by mixing $1 \mu$ l of ACTH $(1 \mathrm{mg} / \mathrm{ml})$ with $39.5 \mu \mathrm{l}$ of $0.1 \%$ trifluoroacetic acid (TFA) to obtain a $10 \mathrm{pmol} / \mu \mathrm{l}$ stock solution. This can be stored at $-20{ }^{\circ} \mathrm{C}$ for future use.

3. Prepare a fresh working ACTH solution ( $1 \mathrm{pmol} / \mu \mathrm{l})$ by taking $1 \mu \mathrm{l}$ of the $10 \mathrm{pmol} / \mu \mathrm{l}$ stock solution, mixing with $9 \mu \mathrm{l} 0.1 \%$ TFA, and then mixing $(1: 1)$ with $10 \mu \mathrm{l}$ of the CHCA matrix solution to obtain a $500 \mathrm{fmol} / \mu \mathrm{l}$ concentration.

4. Prepare TAG standards at $10 \mathrm{mg} / \mathrm{ml}$ in 3:2 C:M for MALDI instrument calibration (e.g. tricaprin [470.361 Da], tricaprylin [554.455 Da], trilaurin [638.549 Da], tripalmitin [722.642 Da], tripalmitolein [800.689 Da], trimyristin [806.736 Da], triolein [884.783 Da], tri-11-eicosenoin [968.877 $\mathrm{Da}$, and trierucin [1052.971 Da]).

5. Prepare triolein at $10 \mathrm{mg} / \mathrm{ml}$ in 3:2 C:M for an external lock-mass calibration TAG standard.

6. Dissolve the stored TAG samples in hexane to a $10 \mathrm{mg} / \mathrm{ml}$ solution.

7. Prepare a $0.5 \mathrm{M}(77.06 \mathrm{mg} / 1.0 \mathrm{ml})$ stock solution of 2,5-dihydroxybenzoic acid (DHB) with $90 \%$ methanol for use as sample and standard matrix. Also prepare a $1.0 \mathrm{M}(2.0 \mathrm{~g} / 50.0 \mathrm{ml})$ solution of $\mathrm{NaOH}$. Cover the tube with $\mathrm{DHB}$ solution using aluminum foil to protect from light.

8. Mix (in pre-washed tubes) $10.0 \mu \mathrm{l} \mathrm{DHB}$ matrix, $10.0 \mu \mathrm{l}$ sample or standard, and $5.0 \mu \mathrm{l} 1.0 \mathrm{M} \mathrm{NaOH}$. Mix and briefly centrifuge the tube to bring mixture to the bottom.

9. Spot $1.0 \mu \mathrm{l}$ of standard, sample, or ACTH onto a MALDI stainless-steel target plate and place in a desiccator until dry. Place the target plate into the instrument for data acquisition.

10. Perform MALDI-TOF MS analyses in positive reflectron mode. Tune and calibrate the instrument as described by the instrument's manufacturer using the ACTH and TAG standard solutions.

11. Acquire spectra for each sample spotted on the target plate (consistent with instrument specifications; parameters for this work were $5 \mathrm{~Hz}$ laser firing rate, $\sim 100$ shots per spot to obtain an average spectrum). After smoothing and subtracting the background from MALDI spectra, process ion peaks manually with the online search engine LIPID MAPS (www.lipidmaps.org/tools/ms/glycerolipids_batch).

12. Copy and paste the list spectra into the list of precursor ions and intensity box. Limit the search to acyl composition desired. Identify TAGs by the mass/charge $(\mathrm{m} / \mathrm{z})$ ratios from ions present in the spectrum for each sample. If fatty acid methyl ester (FAME) percentages are available from separate GC/MS analysis, add these data to obtain probabilities of TAGs present.

INSTRUMENT: The mass spectrometer used in this study is a Waters MALDI Micro MX (equipped with a $337 \mathrm{~nm} 20 \mathrm{~Hz} \mathrm{~N}_{2}$ laser). Any manufacturer's MALDI instrument with positive reflectron mode capability can be used. General settings used are pulse voltage, 2,000 V; reflectron, 5,200 V; source, 15,000 V, with data acquisition using MassLynx software (ver. 4.0). These operating conditions provide mass resolution greater than 12,000 .

\section{Representative Results}

The extraction method for isolating total lipids from tissue described by Folch ${ }^{30}$ is a straightforward procedure, which is adapted here. After tissue extraction and solvent evaporation, the lipids often appear as a yellowish film. The yellow color most likely is from protein contaminants, which can be removed by performing a liquid-liquid extraction. This additional sample processing is not needed in this procedure because preparative TLC separates the TAG fraction from such contaminants. The addition of fresh anhydrous sodium sulfate at all filtering stages helps reduce water contamination that affects accurate lipid weight determinations.

Mammalian integumentary lipid analyses by preparative TLC with $\mathrm{H}: \mathrm{E}: \mathrm{A}$ as the mobile phase will usually resolve four distinct bands corresponding to (starting from origin) sterols, FFAs, TAGs, and sterol esters/wax esters/squalene (Figure 1). On occasion when using analytical high performance (HP) TLC with the H:E:A mobile phase, the sterol esters, waxy esters, and squalene will separate and appear as three separate bands. Under the conditions used in the present study, the sterol/waxy esters are not separated. If these bands are of interest, the mobile phase can be switched to isooctane:ethyl ether $(95: 5 \mathrm{v} / \mathrm{v})$, and the HPTLC plate can be analyzed by scanning densitometry. Other factors can cause poor separation. These are usually eliminated by placing the filter paper in the chamber, applying grease for a tight seal on the lid, equilibrating the chamber overnight, and keeping clean TLC chambers, to obtain consistent quality TLC separations and data.

Representative MALDI-TOF mass spectra obtained for TAGs isolated from the Eastern red bat are shown in Figures 2 and 3. These spectra contain TAG ion peaks in the mass range between $\mathrm{m} / \mathrm{z} 850$ - 910, which is typical for TAGs isolated from non-aquatic mammals. The addition of $1.0 \mathrm{M} \mathrm{NaOH}$ promotes singly charged $\mathrm{Na}^{+}$ions that are more stable than $\mathrm{H}^{+}$ions. In addition to stability, the absence of $\mathrm{H}^{+}$and $\mathrm{K}^{+}$ions increases ease of spectrum analysis. The $m / z 850$ - 910 ion peaks correspond to 16:0, 18:0, 18:1, and 18:2 FA moieties being the dominant acyl constituents in TAGs (Table 1). Possible FA moieties of TAGs can be initially determined by total ion $\mathrm{m} / \mathrm{z}$ present in MALDI-TOF MS spectra, and differences among species and individuals deduced. However, if the specific ratios of acyl content are required, then MS/MS or gas chromatography (GC/MS) must be used. Further information on acyl ratios can be deduced by observing the peaks in the diacylglycerides region of the spectrum (Figure 4). Diacylglycerides are produced from TAG fragmentation in the MALDI source and can be found in the $m / z 590$ - 650 region. TAG fragmentation can be increased by omitting the addition of $1.0 \mathrm{M} \mathrm{NaOH}^{16}$. Eastern red bat wing tissue is characterized by a dominant peak at $\mathrm{m} / \mathrm{z} 879.7$ and hair tissue with a dominant peak at $\mathrm{m} / \mathrm{z} 881.8$ (Figure 2 and 3 respectively). Peaks at $\mathrm{m} / \mathrm{z}$ 907.8, 879.7, and 855.7 (POP, PPoS) are approximately even in intensity ( 50\%) in hair tissue with the peak at 853.7 being $\sim 40 \%$.

\begin{tabular}{|l|l|l|}
\hline Composition & $\begin{array}{l}\text { Elemental } \\
\text { Composition }\end{array}$ & Observed Mass \\
\hline $\mathrm{Na}^{+}$TAGs & & $\mathrm{Na}^{+}$TAGs \\
\hline $\mathrm{SSO}$ & $\mathrm{C}_{57} \mathrm{H}_{108} \mathrm{O}_{6}$ & 911.8 \\
\hline
\end{tabular}




\begin{tabular}{|c|c|c|}
\hline OOS, LSS & $\mathrm{C}_{57} \mathrm{H}_{106} \mathrm{O}_{6}$ & 909.8 \\
\hline OOO, LnSS, LSO & $\mathrm{C}_{57} \mathrm{H}_{104} \mathrm{O}_{6}$ & 907.8 \\
\hline LOO, LLS & $\mathrm{C}_{57} \mathrm{H}_{102} \mathrm{O}_{6}$ & 905.8 \\
\hline LLO, OOLn & $\mathrm{C}_{57} \mathrm{H}_{100} \mathrm{O}_{6}$ & 903.7 \\
\hline LLL & $\mathrm{C}_{57} \mathrm{H}_{98} \mathrm{O}_{6}$ & 901.7 \\
\hline LLLn & $\mathrm{C}_{57} \mathrm{H}_{96} \mathrm{O}_{6}$ & 899.7 \\
\hline LLnLn & $\mathrm{C}_{57} \mathrm{H}_{94} \mathrm{O}_{6}$ & 897.7 \\
\hline LnLnLn & $\mathrm{C}_{57} \mathrm{H}_{92} \mathrm{O}_{6}$ & 895.7 \\
\hline OSP & $\mathrm{C}_{55} \mathrm{H}_{104} \mathrm{O}_{6}$ & 883.8 \\
\hline LSP, OOP, SOPo & $\mathrm{C}_{55} \mathrm{H}_{102} \mathrm{O}_{6}$ & 881.8 \\
\hline LOP, LnSP, LSPo & $\mathrm{C}_{55} \mathrm{H}_{100} \mathrm{O}_{6}$ & 879.7 \\
\hline LLP, LnOP, LOPo & $\mathrm{C}_{55} \mathrm{H}_{98} \mathrm{O}_{6}$ & 877.7 \\
\hline LnLP, LLPo, LnOPo & $\mathrm{C}_{55} \mathrm{H}_{96} \mathrm{O}_{6}$ & 875.7 \\
\hline LnLnP, LnLPo & $\mathrm{C}_{55} \mathrm{H}_{94} \mathrm{O}_{6}$ & 873.7 \\
\hline LnLnPo & $\mathrm{C}_{55} \mathrm{H}_{92} \mathrm{O}_{6}$ & 871.7 \\
\hline PPS & $\mathrm{C}_{53} \mathrm{H}_{102} \mathrm{O}_{6}$ & 857.8 \\
\hline POP, PPoS & $\mathrm{C}_{53} \mathrm{H}_{100} \mathrm{O}_{6}$ & 855.7 \\
\hline OOM, PPL, PoPoS, POPo & $\mathrm{C}_{53} \mathrm{H}_{98} \mathrm{O}_{6}$ & 853.7 \\
\hline PPLn, PPoL, PoPoO, MyOO & $\mathrm{C}_{53} \mathrm{H}_{96} \mathrm{O}_{6}$ & 851.7 \\
\hline LLM, LnOM & $\mathrm{C}_{53} \mathrm{H}_{94} \mathrm{O}_{6}$ & 849.7 \\
\hline PPP, SSLa & $\mathrm{C}_{51} \mathrm{H}_{98} \mathrm{O}_{6}$ & 829.7 \\
\hline PPPo, OSLa & $\mathrm{C}_{51} \mathrm{H}_{96} \mathrm{O}_{6}$ & 827.7 \\
\hline PPoPo, PMyO & $\mathrm{C}_{51} \mathrm{H}_{94} \mathrm{O}_{6}$ & 825.7 \\
\hline LnLnLa & $\mathrm{C}_{51} \mathrm{H}_{86} \mathrm{O}_{6}$ & 817.6 \\
\hline MMS, SLaP, PPM & $\mathrm{C}_{49} \mathrm{H}_{94} \mathrm{O}_{6}$ & 801.7 \\
\hline SLaPo, PPoM, PPMy & $\mathrm{C}_{49} \mathrm{H}_{92} \mathrm{O}_{6}$ & 799.7 \\
\hline PoPoM, OOCa & $\mathrm{C}_{49} \mathrm{H}_{90} \mathrm{O}_{6}$ & 797.7 \\
\hline MMP & $\mathrm{C}_{47} \mathrm{H}_{90} \mathrm{O}_{6}$ & 773.7 \\
\hline MMPo, OCaP & $\mathrm{C}_{47} \mathrm{H}_{88} \mathrm{O}_{6}$ & 771.7 \\
\hline $\mathrm{OCaPo}$ & $\mathrm{C}_{47} \mathrm{H}_{86} \mathrm{O}_{6}$ & 769.6 \\
\hline MMM, PPCa, PMLa & $\mathrm{C}_{45} \mathrm{H}_{86} \mathrm{O}_{6}$ & 745.6 \\
\hline PoPCa, PoMLa & $\mathrm{C}_{45} \mathrm{H}_{84} \mathrm{O}_{6}$ & 743.6 \\
\hline PoPoCa & $\mathrm{C}_{45} \mathrm{H}_{82} \mathrm{O}_{6}$ & 741.6 \\
\hline LaLaP, MMLa, MCaP & $\mathrm{C}_{43} \mathrm{H}_{82} \mathrm{O}_{6}$ & 717.6 \\
\hline LaLaPo & $\mathrm{C}_{43} \mathrm{H}_{80} \mathrm{O}_{6}$ & 715.6 \\
\hline $\mathrm{OO}$ & $\mathrm{C}_{39} \mathrm{H}_{72} \mathrm{O}_{5}$ & 643.5 \\
\hline OL & $\mathrm{C}_{39} \mathrm{H}_{70} \mathrm{O}_{5}$ & 641.5 \\
\hline LL & $\mathrm{C}_{39} \mathrm{H}_{68} \mathrm{O}_{5}$ & 639.5 \\
\hline SP & $\mathrm{C}_{37} \mathrm{H}_{72} \mathrm{O}_{5}$ & 619.5 \\
\hline OP & $\mathrm{C}_{37} \mathrm{H}_{70} \mathrm{O}_{5}$ & 617.5 \\
\hline LP & $\mathrm{C}_{37} \mathrm{H}_{68} \mathrm{O}_{5}$ & 615.5 \\
\hline
\end{tabular}


Table 1. Fatty acid composition, elemental composition, and isotopic mass of sodiated adducts of triacylglycerides and diacylglycerides. $\mathrm{Ln}=$ linolenic acid (18:3), $\mathrm{L}=$ linoleic acid (18:2), $\mathrm{O}=$ =leic acid (18:1), $S=$ stearic acid (18:0), $P=$ palmitic acid (16:0), Po=palmitoleic acid (16:1), M=myristic acid (14:0), My=myristoleic acid (14:1) La=lauric acid (12:0), Ca=Capric acid (10:0).

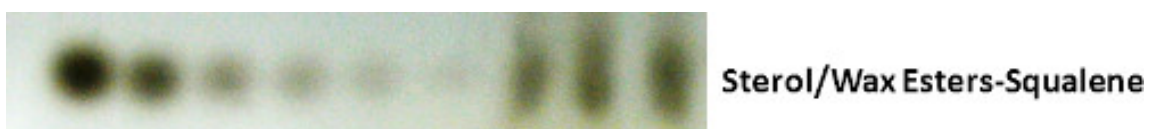

\section{Triacylglycerides}

\section{Free Fatty Acyls}

\section{Sterol}

Figure 1. Thin-layer chromatogram of broad lipid class separation by hexane:diethyl ether:acetic acid (80:20:2 v/v/v) as the mobile phase. The band between sterol and FFA was not identified by a standard but may be a fatty alcohol or wax diester.

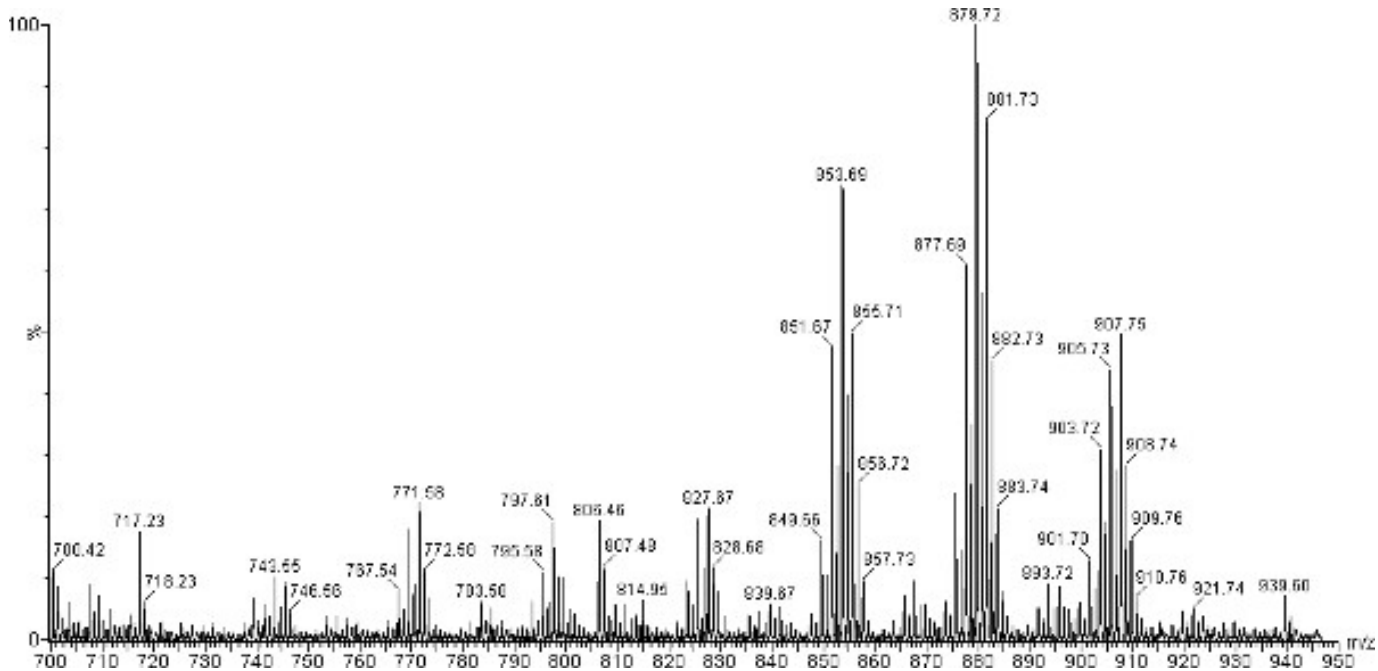

Figure 2. Expanded TAG region of MALDI-TOF mass spectrum of sodiated TAGs $(\mathrm{m} / \mathrm{z} 700-950)$ from Eastern red bat (L. borealis) wing tissue. Peaks identified at $\mathrm{m} / \mathrm{z}$ 853.7 (OOM, PPL, PoPoS, POPo) and $\mathrm{m} / \mathrm{z} 879.7$ (LOP, LnSP, LSPo). Click here to view larger figure. 


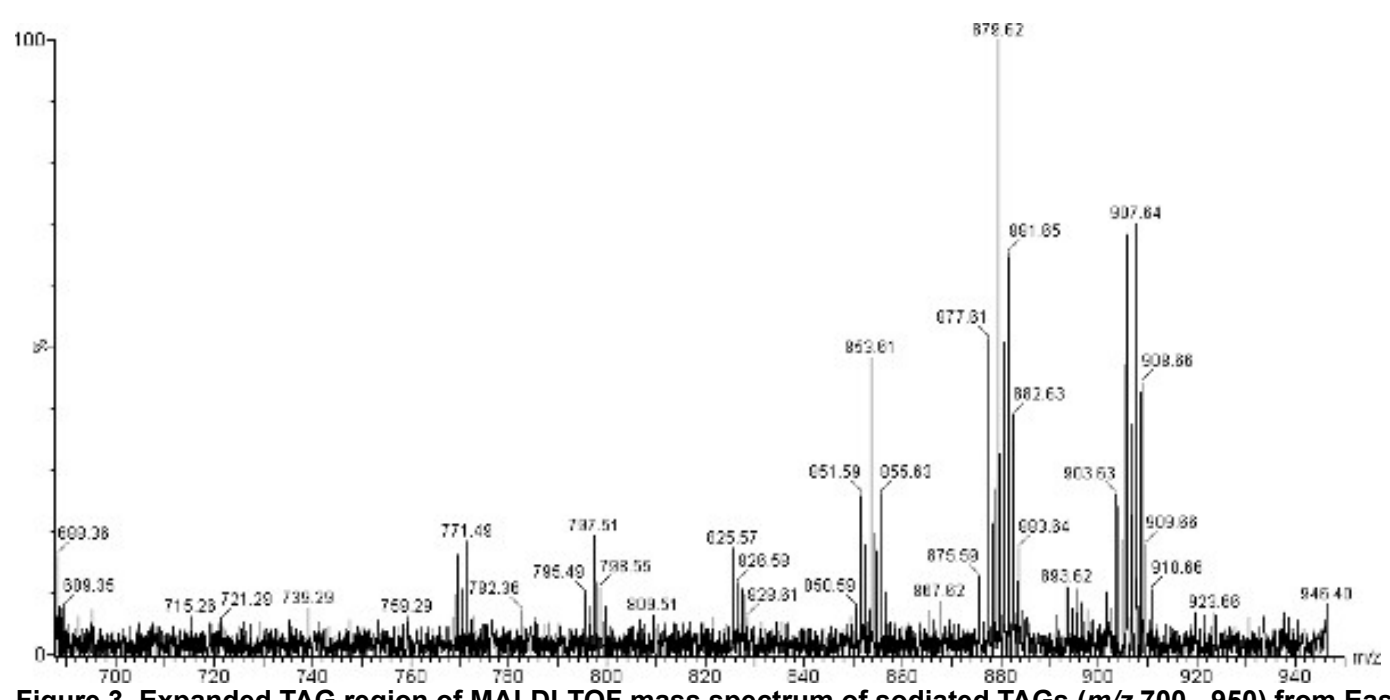

Figure 3. Expanded TAG region of MALDI-TOF mass spectrum of sodiated TAGs $(\mathrm{m} / \mathrm{z} 700-950)$ from Eastern red bat ( $L$. borealis) hair tissue. Peaks identified at $\mathrm{m} / \mathrm{z} 905.8$ (LOO, LLS) and $\mathrm{m} / \mathrm{z} 907.8$ (OOO, LnSS, LSO). Click here to view larger figure.

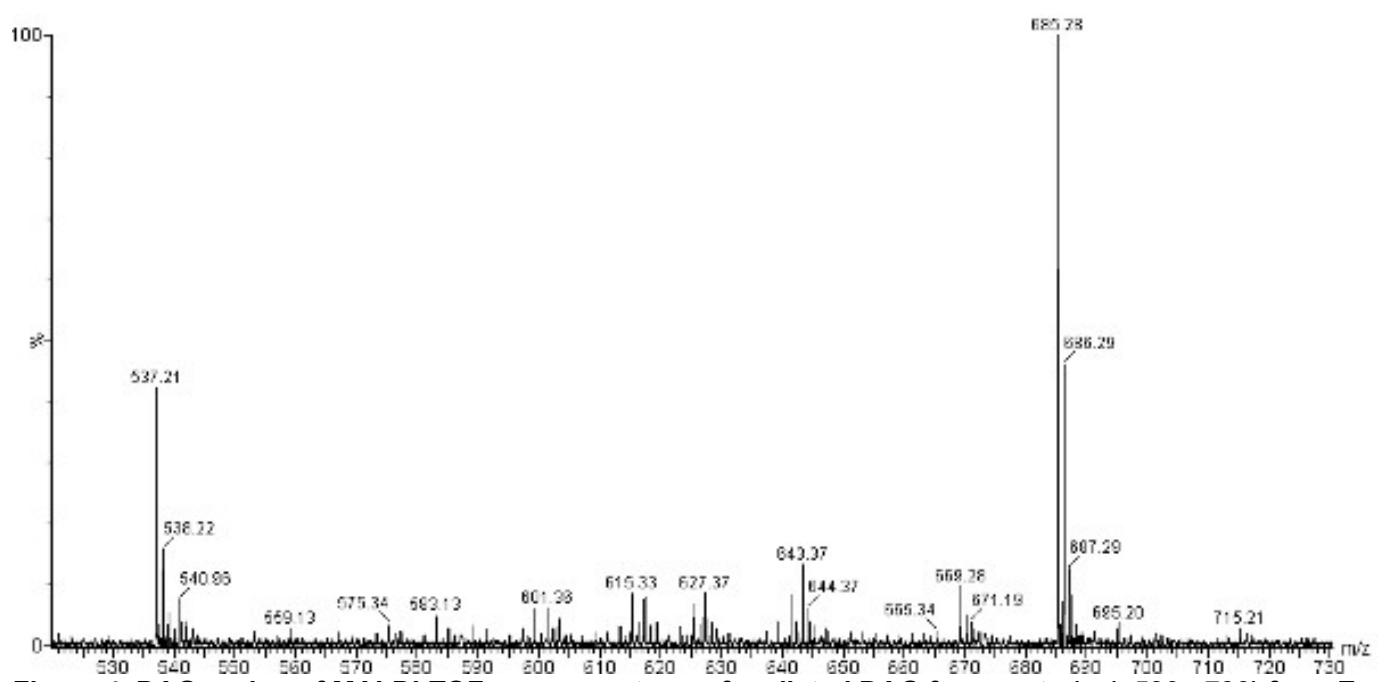

Figure 4. DAG region of MALDI-TOF mass spectrum of sodiated DAG fragments ( $\mathrm{m} / \mathrm{z} 530$ - 730$)$ from Eastern red bat $(L$. borealis) wing tissue. Peaks identified at $\mathrm{m} / \mathrm{z} 643.5(\mathrm{OO})$ and $\mathrm{m} / \mathrm{z} 615.5$ (LP). Click here to view larger figure.

\section{Discussion}

This paper presents a simple and robust method for separating broad lipid classes isolated from mammalian integument by preparative TLC and determining TAG profiles by MALDI-TOF MS, without time-consuming derivatization of the lipid molecules. The critical steps in producing quality spectra of TAGs with MALDI-TOF MS include: 1) Successful extraction of the compound with minimal contamination or oxidation; 2) Sufficient separation and isolation by chromatography; and 3) High resolution and mass accuracy by MALDI-TOF MS.

This paper demonstrates the method by extracting and separating the neutral lipid fraction from the plagiopatagium of the Eastern red bat to obtain TAG MS profiles. While the present study used a bat species (Mammalia: Chiroptera) these methods can be extended to study integumentary lipids of any mammalian species. Bat integument is characterized by being predominantly cholesterol, with lower amounts of TAGs, FFAs, squalene, and sterol/wax esters. Sebum lipid ratios in bats differ from humans in that squalene is present in low amounts (as opposed to up to $16 \%$ in humans), whilst cholesterol occurs in larger ratios (1-7\% in humans but $26-62 \%$ in bats) $)^{22,31}$. Human hairs contain about $3 \%$ TAGs, while ratios up to $28 \%$ are found in Eastern red bat hair. The extraction of lipid samples from bats is similar for other species. While in this study cotton balls soaked in solvent are used to remove sebum, one can also invert a vial or sample tube containing solvent onto the surface of the integument multiple times. Specialized tape products also provide alternative means to extract surface lipids ${ }^{32}$. A critical part of a proper lipid extraction is to minimize contamination from skin oils. This is easily accomplished by keeping a squeeze bottle with methanol and spraying all glassware and utensils, wiping utensils with a tissue between all samples and wearing examination gloves. Oxidation of polyunsaturated acyls is prevented through the addition of $\mathrm{BHT}$, and it should be used regardless of the temperature samples are stored at.

Biomolecule analysis usually requires a chromatographic step to separate molecules of interest from contaminants. TLC is used in this method, which avoids instrumentation requirements for gas or liquid chromatography and requires less technical experience to achieve robust and 
repeatable results. Depending on the lipid class of interest, many different mobile phases can be incorporated. Furthermore, the use of HPTLC plates and scanning densitometry can be used to achieve quantitative results. While the variations of TLC methods are too numerous to list here, some common mobile phases used in lipid TLC include chloroform:methanol:water for separation of phospholipids and glycolipids or isooctane:ethyl ether for separation of non-polar lipids ${ }^{28}$. In terms of separating TAGs from other lipid classes, the H:E:A solvent system works consistently and provides comparable results.

Another advantage for using TLC is that bands of interest can be rapidly profiled using MALDI-TOF MS without prior derivatization of the analytes. In this study the silica is removed from the TLC plate, and the analyte is eluted from it by sonication in a solvent and subsequent centrifugation to separate the adsorbent and evaporation of the eluting solvent. Alternatively, matrix may be applied directly onto analyte bands separated on TLC plates and then directly analyzed by MALDI-TOF MS ${ }^{33}$. Successful profiling by MALDI-TOF MS does rely on sufficient sample preparation and the operator's proficiency with tuning and calibrating the instrument. The instrument should be calibrated daily with standards covering molecular weight range appropriate for the molecules of interest. The suitable sensitivity and resolution $(e . g . \geq 10,000)$ of the equipment should also be confirmed daily with ACTH.

The sebaceous lipid constituents found on the surface of mammalian integument may play a role in colonization by bacterial/fungal pathogens. Therefore knowledge of the chemical composition among species and individuals may provide clues about processes of human and wildlife diseases. Intraspecific differences among diseased and healthy individuals may represent clinical signs that aid in disease detection and diagnosis. Furthermore, if specific compounds that inhibit microbial growth are present, these may be identified for use in disease treatment and prevention.

\section{Disclosures}

The authors declare no competing financial interests.

\section{Acknowledgements}

Assistance was provided by Scott Treece, Katelyn Arter, Jeremy Ragsdell, Tony LaMark James, Amy Fischer, Hannah Blair, and Cheyenne Gerdes during the development of laboratory methods. We would like to thank the Medina-Bolivar Laboratory (Luis H. Nopo-Olazabal; Arkansas Biosciences Institute) for assistance with TLC scanning densitometry. MALDI-TOF MS used for this project was provided through the NSF EPSCoR, RII: Arkansas ASSET Initiative P3 Center (EPS-0701890) in the Arkansas Biosciences Institute. Funding was provided by a U.S. Fisheries and Wildlife Service/Arkansas State Wildlife Grant, the National Speleological Society, and The Center for North American Bat Research and Conservation at Indiana State University.

\section{References}

1. Pappas, A., Anthonavage, M., \& Gordon, J.S. Metabolic fate and selective utilization of major FAs in human sebaceous gland. Journal of Investigative Dermatology. 118 (1), 164-171 (2002).

2. Nicolaides, N., Hwei, H.C., \& Rice, G.R. The skin surface lipids of man compared with those of eighteen species of animals. Journal of Investigative Dermatology. 51 (2), 83-89 (1968).

3. Desbois, A.P. \& Smith, V.J. Antibacterial free fatty acids: activities, mechanisms of action and biotechnological potential. Applied Microbiology and Biotechnology. 85 (6), 1629-1642 (2010).

4. Munoz-Garcia, A. \& Williams, J.B. Cutaneous water loss and lipids of the stratum corneum in Dusky Antbirds, a lowland tropical bird. Condor. 109 (1), 59-66 (2007).

5. Catala, A. The function of very long chain polyunsaturated fatty acids in the pineal gland. Biochimica et Biophysica Acta. 1801, 95 - 99 (2010).

6. Stahl, J., Niedorf, F., \& Kietzmann, M. Characterization of epidermal lipid composition and skin morphology of animal skin ex vivo. European Journal of Pharmacology. 72 (2), 310-316 (2009).

7. Picardo, M., Ottaviani, M., Camera, E., \& Mastrofrancesco, A. Sebaceous gland lipids. Dermato-Endocrinology. 1 (2), 68-71 (2009).

8. Ro, B.I. \& Dawson, T.L. The role of sebaceous gland activity and scalp microfloral metabolism in the etiology of seborrheic dermatitis and dandruff. Journal of Investigative Dermatology. 10, 194-197 (2005).

9. Davoudi, S.M., Sadr, B., et al. Comparative study of skin sebum and elasticity level in patients with sulfur mustard-induced dermatitis and healthy controls. Skin Research and Technology. 16 (2), 237-242 (2010).

10. Zampeli, V.A.,Makrantonaki, E.,Tzellos, T., \& Zouboulis, C.C. New pharmaceutical concepts for sebaceous gland diseases: implementing today's pre-clinical data into tomorrow's daily clinical practice. Current Pharmaceutical Biotechnology. 13 (10), 1898-1913 (2012).

11. Horton, H.R., Moran, L.A., et al. Principles of Biochemistry. Prentice Hall, Englewood Cliffs, NJ, (1993).

12. Fahy, E., Subramaniam, S., et al. A comprehensive classification system for lipids. European Journal of Lipid Science and Technology. 107 (5), 337-364 (2005).

13. Fahy, E., Subramaniam, S., et al. Update of the LIPID MAPS comprehensive classification system for lipids. Journal of Lipid Research. $\mathbf{5 0}$ (5), S9-S14 (2009).

14. Fuchs, B., Süß, R., Nimptsch, A., \& Schiller, J. 2009. MALDI-TOF-MS directly combined with TLC: A review of the current state. Chromotagraphia. 69, S95 - S105 (2009).

15. Savary, B.J., \& Vasu, P. In Recombinant Gene Expression, Reviews and Protocols., $3^{\text {rd }}$ Ed., Lorence, A., ed., Humana Press, New York, NY, (2011).

16. Gidden, J., Liyanage, R., Durham, B., \& Lay, J.O. Reducing fragmentation observed in the matrix-assisted laser desorption/ionization time-offlight mass spectrometric analysis of triacylglycerols in vegetable oils. Rapid Communications in Mass Spectrometry. 21, 1951-1957 (2007).

17. Fuchs, B. \& Schiller, J. Application of MALDI-TOF mass spectrometry in lipidomics. European Journal of Lipid Science and Technology. 111 (1), 83-98 (2009). 
18. Fuchs, B., Süß, R., \& Schiller, J. An update of MALDI-TOF mass spectrometry in lipid research. Progress in Lipid Research. 49 (4), $450-475$ (2010).

19. Karas, M., Bachmann, D., \& Hillenkamp, F. Influence of the wavelength in high-irradiance ultraviolet laser desorption mass spectrometry of organic molecules. Analytical Chemistry. 57 (14), 2935-9 (1985).

20. Hillenkamp, F., Karas, M., Holtkamp, D., \& Klusener, P. Energy deposition in ultraviolet laser desorption mass spectrometry of biomolecules. International Journal of Mass Spectrometry and lon Processes. 69 (3), 265-276 (1986).

21. Knochenmuss, R. In Electrospray and MALDI Mass Spectrometry: Fundamentals, Instrumentation, Practicalities, and Biological Applications., $2^{\text {nd }}$ ed., Cole, R.B. e.d., John Wiley and Sons, NJ, 149-262 (2010).

22. Pannkuk, E.L., Gilmore, D., Savary, B.J., \& Risch, T.S. Triacylglyceride (TAG) profiles of integumentary lipids isolated from three bat species determined by matrix-assisted laser desorption - ionization time-of-flight mass spectrometry (MALDI - TOF MS). Canadian Journal of Zoology. 90 (9), 1117-1127 (2012).

23. Blehert, D., Hicks, A.C., et al. Bat white-nose syndrome: An emerging fungal pathogen? Science. 323 (5911), 227-228 (2009).

24. Gargas, A., Trest, M.T., et al. Geomyces destructans sp. nov. associated with bat white-nose syndrome. Mycotaxon. 108, 147-154 (2009).

25. Lorch, J.M., Meteyer, C.U., et al. Experimental infection of bats with Geomyces destructans causes white-nose syndrome. Nature. 480 (7377), 376-378 (2011).

26. Frick, W.F., Pollock, J.F., et al. An emerging disease causes regional population collapse of a common North American bat species. Science. 329 (5992), 679-682 (2010).

27. Boyles, J.G., Cryan, P.M., McCracken, G.F., \& Kunz, T.H. The economic importance of bats in agriculture. Science. 332 (6025), 41-42 (2011).

28. Sikes, R.S., Gannon, W.L., et al. Guidelines of the American Society of Mammalogists on the use of wild mammals in research. Journal of Mammalogy. 92 (1), 235-253 (2011).

29. Law, S., Wertz, P.W., Swartzendruber, D.C., \& Squier, C.A. Regional variation in content, composition, and organization of porcine epithelial barrier lipids revealed by thin layer chromatography and transmission electron microscopy. Archives of Oral Biology. 40 (12), $1085-1091$ (1995).

30. Folch, J., Lees, M., \& Sloane Stanley, G.H. A simple method for the isolation and purification of total lipids from animal tissues. Journal of Biological Chemistry. 226 (1), 497-509 (1957).

31. Nicolaides, N. Skin lipids: Their biochemical uniqueness. Science. 186 (4158), 19-24 (1974).

32. Camera, E., \& Ludovici, M., et al. Comprehensive analysis of the major lipid classes in sebum by rapid resolution high-performance liquid chromatography and electrospray mass spectrometry. Journal of Lipid Research. 51, 3377-3388 (2011).

33. Fuchs, B., Süß, R., et al. Lipid analysis by thin-layer chromatography- A review of the current state. Journal of Chromatography A. 1218 (19), 2754-2774 (2011). 